\title{
Emergent strategies for sustainable rural tourism development of Gashaka-Gumti National Park, Nigeria
}

\author{
W. Nzeda Tagowa ${ }^{1} \&$ U. Nformi Buba ${ }^{2}$ \\ ${ }^{I}$ Department of Political Science and International Relations, \\ Taraba State University, Nigeria \\ ${ }^{2}$ Department of Biological Sciences, Taraba State University, Nigeria
}

\begin{abstract}
The Gashaka Gumti National Park (GGNP) is located along the central part of the North-Eastern border of Nigeria and Cameroon in Taraba and Adamawa states. The Park is the largest and most diverse enclaves in Nigeria and is an endowed home of extensive biodiversity, natural and socio-cultural potentials. Its expanse has the capacity to accommodate local and international tourism. The Gashaka Primate Project (GPP), being funded by the North of England Geological Society, London, through the Chester Zoo 2000, has, since 2000, undertaken a series of biodiversity activities in support of the Nigerian Biodiversity programme, to enhance sustainable rural tourism development of the area. This study, therefore, reviews the activities of GPP as an example of the emergent strategies for sustainable rural tourism development in Nigeria. The study equally analyses the various activities undertaken in the project which, among others, include biodiversity research and documentation, ecosystem conservation, human-wild life conflicts, capacity building and environmental protection and preservation. These activities are essential prerequisites for sustainable rural tourism development. The paper further examines the major impact of the project, challenges and constraints as well advances new conservation strategies for enhancing sustainable rural tourism development of the GGNP. The paper makes some recommendations which surround the necessity for further collaboration of a broad range of the society to push forward the new strategies. This requires holistic approach to tourism development which will continue to impact on biodiversity conservation and socio-economic development of the local communities in and around the Park.
\end{abstract}


Keywords: Gashaka Gumti national park (GGNP), Gashaka primate project $(G P P)$, biodiversity, ecosystem conservation, sustainable rural tourism, primate socio-ecology, local community, community relations, park rangers, habitat.

\section{Introduction}

National Parks the world over have been created for a combination of reasons ranging from ecological, spiritual, scientific, socio-economic, cultural, and educational, to recreational purposes. In this respect, they provide one of the best ways of safeguarding the earth's living diversities and this makes them vital for the maintenance of life support systems on the planet, and for the improvement of human social and economic conditions [1]. Thus, national parks have positive contributions to the economic, cultural and spiritual wellbeing of societies. The Gashaka Gumti National Park (GGNP) is one of Nigeria's and Africa's conservation and protected area that is increasingly being recognized as "a biodiversity hotspot" [2]. Biodiversity has to do with the number of different plants and animals found in an area. The GGNP has a combination of vegetation, topography, altitude and climate that provide the area with a unique range of habitats that support an ecosystem of exceptionally high biodiversity.

The GGNP was established to play a number of conservation roles such as biodiversity conservation, conservation of potentially valuable genetic resources, protection of cultural biodiversity and support for traditional livelihood, education, natural laboratory research and support for rural development [1]. The combined effect of these varieties of roles is to enhance tourism both at local and international levels.

Despite the fact that tourism formed an integral part of the objectives that led to the establishment of this National Park, "small paradise inside Nigeria," its tourism capacity and potentials remain unknown or very little was known to the outside world until the coming of the Gashaka Primate Project (GPP) [2]. GPP directed by Professor Volker Sommer of University College London (UCL), is a research based outreach centred on research and conservation at GGNP. Its academic office is the Department of Anthropology, UCL. The Project's major research interests are biodiversity, socio-ecology, community relations and public engagement.

Research is carried out by senior scientists, Doctoral and Post-Doctoral, Masters and undergraduates students and volunteers. GPP affiliates come from England, Scotland, Netherlands, Germany, Switzerland, Austria, Portugal, France, Italy, Greece, Argentina, USA, Canada, Ivory Coast and Nigeria. GPP works closely with the Nigeria National Park Conservation Unit, NonGovernmental Organizations (NGOs) such as WWF-UK, Nigeria Conservation Foundation, as well as local communities. Notable GPP conservation activities include (a) funding and supervising African students (b) facilitation of park-wide communication system (hand-held radios/walky-talky), which enable rangers operations, (c) eco-tourism development, and (d) demarcation of the entire GGNP border (length: $260 \mathrm{~km}$ ). All these activities were sponsored by the outreach programme of the Chester Zoo/UK. This paper therefore analyses some 
of the activities of the GPP as an example of the emergent strategies for sustainable rural tourism development of the GGNP [2].

\section{Materials and methods}

The study area is GGNP as described in the GPP. GGNP has an area of about $6,600 \mathrm{~km}^{2}$ and straddles the Cameroonian border. GGNP demarcates the northern edge of the Cameroonian Highlands and Africa's Gulf of Guinea forests [2]. GGNP is divided into the mountainous Gashaka sector in the South in Taraba State and the relatively flat Gumti sector in the North in Adamawa State of Nigeria. It comprises different habitat types and includes flat grassland, guinea savannah-woodlands, riverine and gallery forests, lowland rainforests, montane forests and montane grasslands.

These forests are dominated by woody species of mostly tall trees that cut deep and provide unceasing shade over the ground, and are too dark to support the growth of grass. Tropical rainforests are a special type of forests which are only found in regions of high rainfall. The Park lies $11 \mathrm{~km}$ from the nearest village of Gashaka. Gashaka Primate Project (GPP) maintains a field station at Kwano village which is $583 \mathrm{~m}$ above sea level. The weather in Kwano is generally pronounced wet and dry depending on the season with corresponding fluctuations in temperature and humidity. The mean minimum temperature is $20.9^{\circ} \mathrm{C}$ while the mean maximum is $31.9^{\circ} \mathrm{C}$. Heavy downpours from mid-April to mid-November are followed by 5 months of very little or no rainfall. The yearly average rainfall is $1,973 \mathrm{~mm}$ (ranging from 1,683 to $2,337 \mathrm{~mm}$ ). Visitors to the Park can enjoy the lush forests, wide sweeping grasslands; cool highland plateaus, rugged mouldy mountains, abundant wildlife, and fascinating ethnic cultures that are combined within one protected area [3].

Data collected from the activities of GPP from 2000 to 2011 were carefully selected and reviewed/analysed as they affect sustainable rural tourism. The GPP compilations were studied as major inputs in the planning and conservation of the GGNP and their positive impact on sustainable tourism development established. The study is principally descriptive and it emanates from the review and analysis of activities of the GPP as well as information and literature retrieved from GPP and GGNP websites.

\section{Analysis of the Gashaka primate project (GPP)}

Research in national parks and protected areas provide Information and interpretive talks and displays to visitors' need to learn more about the tourist sites as part of human development and management for sustainable tourism [2]. The GPP was not only aimed at field study and analysis of Nigeria's most unique biological, physical and cultural resources but also providing information that would influence policy and thereby improve tourism management and rural community development. The Project covers three areas of research and documentation including biodiversity research, non-human socio-ecology (baboons and chimpanzees), community relations and public engagement. These 
research and documentation were carried out through various activities of constructions, capacity building, and ecosystem conservation and attempts to resolve human-wild life conflicts. The GPP and its research agenda has a significant impact on conservation of the Park and thus serve as examples of the emergent strategies for sustainable tourism development.

\subsection{Biodiversity research}

The Gashaka Gumti is part of the areas that has been recognized as a biodiversity hotspot of West Africa with rich plant and animal species whose levels of endemism are exceptionally high [2]. This has favoured the development of diverse flora and fauna and good for human habitation as the result of large altitudinal ranges, moist and warm climate of the surrounding geographical barriers. The landscape is largely relatively inaccessible and this has shielded the terrain against serious commercial logging and other human incursions. The vegetation is described as a mosaic savannah woodland, riverine and lowland rainforest as well as grassland and mountain forest as shelters for:

...carnivores such as civets, golden cat and leopard, ungulates, such as buffalo, bushbuck, duikers, waterbuck, hartebeest, red river hogs, and one of the last remaining populations of giant forest hogs. Rare fresh waterfish, otters as well as sizeable crocodiles and even few hippopotamus strive in the translucent rivers. More than 500 featured species led to the designation of the park as an 'important bird area' [4].

The Park is also a home of diverse diurnal primates such as olive baboons, putty-nosed guenon, mona monkeys, black and white colobus, tantalus monkeys, patas monkeys and grey-cheeked mangabeys. It also provides refuge for the largest surviving population of pan troglodytes vellerosus known as the 'Nigerian chimpanzee' which is one of the animals whose availability red list status has changed from 'endangered' to 'critically endangered' [4].

One of the bases for the biodiversity research in the GGNP was the contention that tropical forests have the most significant terrestrial habitats and hence provide the most significant biodiversity. For example, Daniel Weaver [5] studied the underlying ecological factors that affect the assemblages of two anthropod orders on two physical gradients within the forest covering increasing distance from the edge of the forest to the interior and increasing height from the forest floor to the point at which vegetation interacts with the atmosphere.

He also investigated how anthropogenic activities influence the gradients and subsequently affect the assemblages of the chosen texa forest. His general conclusion was that there is a significant difference in densities between height in the forest, the savannah treatment and distance from the edge of the forest and therefore higher abundance than both mid and high canopy areas [5]. On the basic of this finding, he believes that anthropogenic burning of adjacent savannah has a distinct affect in the dry season with abundance clearly lower at the burnt edge than the internal control plots.

Similarly, the study of the spatial and temporal patterns established community abundance of the structure of dipterans in Kwano which indicated 
that during dry season the ground canopy had significant abundance of dipterans than mid and high canopy. This shows that the change in season has profound effect on the overall abundance of dipterans and where they are found within the vertical column [6]. In addition to other factors that affect tourism destination, the findings of these studies have critical impact on the choice of season for visit to the tourist site.

\subsection{Primate socio-ecology}

The primate socio-ecology of the GPP was concentrated on olive baboons and chimpanzees. The focus was the various social lives of olive baboons and chimpanzees which centred on social correlates of self-directed behaviours, social integration and life history variables, social complexities, environmental stress, primate foods and eating habits as well as potential non-nutritional functions of primates. Others are fission-fusion dynamics of primates, hand preferences, social communication, and crop raiding energetic stress, climate variation in forest living, sociality reproduction, consumption patterns, social identity and cultural traits. The results of these socio-ecological studies made appreciable revelation on the necessity for conservation of the primates of GGNP.

\subsection{Community relations and public engagement}

This aspect of the project involves documentations and establishment of linkages between humans and animals through measuring or influencing change of attitude of the rural communities towards conservation of primates. Thus the research team also undertakes various community relations activities such as film shows, provision of social infrastructure such as rural roads, electrification of the research camp, mapping and assessment of ecosystem degradation sites and taking steps to integrate the GGNP into global GIS technology. The GPP also explored several opportunities for partnerships in biodiversity conservation of GGPN. The high point of such community relations and public engagement is not only the signing of agreement between the Nigerian National Park Service Governing Board (NNPSGB) for further research in the GGNP but also the launching of three important documents, viz, .i) Apes Like Us: Portraits of a Kingship (Bilingual) Edutory Mannhem: Paranoma (2010), ii) Gashaka Primates: Socio-ecology and Conservation in Nigeria's Biodiversity Hotspot (Development in Prinatology; Problems and Prospects), Springer: New York (2011), and iii) Regional Action Plan Action Plan for the Conservation of the Nigeria-Cameroon Chimpanzees (2011) [7].

\section{The GPP as a conservation strategy}

GGNP area reflects a complex pattern of a diverse ecosystem and a corresponding high level of biodiversity that can attract national and international tourism. The vegetal cover and the associated wildlife and human existence which are linked with the climate features fluctuate between wet and 
dry seasons. The current savannah vegetation is derived from the anthropogenic influences dating back to past centuries. The dynamics of the region is described as largely climate-driven which is aided by the past development of complex assemblage of vegetation cover and wildlife which faces a whole catalogue of threats:

Logging is the smallest danger as access is difficult - although many slopes in the Park's wider vicinity have been denuded by the timber industry. More and more immigrants move far away into the buffer zone, with little means of survival other than targeting the natural resources. Several illegal settlements has encroached the park boundaries. Poaching is rampant in the Park's surroundings, and most forests have been shot empty of large animals. Hunters particularly from the across the Cameroonian border, are increasingly targeting the reverse itself [6].

Burning, overgrazing and washing off of the top soil constitute a major menace. Although there is a legal backing to the park, there is actually little constructive engagement of the Park authorities with those whose activities have grave consequences on the Park. Forest rangers have to confront pastoralists who graze cattle, illegal settlers and poachers resulting in violent clashes and therefore little success in conservation activities. This was worsened by lack of border demarcation of the Park. The GPP research project thus becomes a practical approach and most effective strategy for conservation.

\section{1 'Power Island': opening up the park}

Considering the remoteness of the Park, the first task of the GPP was to establish a research camp at Kwano. A 'power island' was then established which constitutes a small independent power plant that supplies stable electricity 24 hours a day from a unique combination of solar panels, a water drive turbine and a computerized 'heart' built into a steel container with 30 dry-cell batteries that store the harvested power [2]. This was used to establish an effective communication system across the wilderness such as repeater-station and dozens or walky-talkies and car radios. This 'power island' and the associated facilities have now become a centre of attraction for visitors, officials and students who now realize that simple advanced technology can have enormous potentials.

The challenge of lack of border demarcation of the Park was addressed by the project through the construction of trails (footpaths), culverts and demarcation of the Nigerian side of the border with beacons. Grazers, settlers and hunters as well as Park operators now know the actual limits of the Park. A 6m wide corridor through the bushland was constructed to establish extents of the Park.

A very important aspect of the GPP is the attempt to understand and reconcile the human-wildlife conflicts in the Park. The major aspect of such conflicts is the crop raiding as a major source of conflict between the primates and the humans living in the enclaves and around the Park. Another source of conflict is the prohibitions on the use of local resources and hunting of all varieties of animals in the Park. 
The source of risks of living in the wildlife enclave was juxtaposed against the perceived benefits. The humans living in the enclave perceived prosperity of livelihood and security as a result of the environment provided by the Park authorities. The established perceived risk of living in or near the Park which is damage to crops was seen as the greatest threat to subsistence agriculture [8]. The olive baboons were noted to have caused the greatest threat as they have the advantage over many other species, because they can use their cheeks pouches to store food when chased and flee to eat elsewhere undisturbed [8]. In many instances, they are often killed or injured during crop raiding. The continued resilience of crop raiding despite harassment by farmers suggests that the costbenefit of living in the enclave by humans far outweigh the benefit and also suggests the cause for continued depreciation of the olive baboons.

However, the film documentaries and film shows among the enclave's communities and even those outside the enclaves had significant impact and positive change of attitude towards conservation of the primates. For the majority of the people, their contact with the primates is their crop depredation or bush meat from poached primates. By watching documentary film shows of animal in their natural habitat, acting in intelligent and social ways, and displaying human-like behaviour, no doubt changed their altitude towards the primates in the form of valuing the protection of the animals and the natural environment they occupied [9]. Thus, films have become a most effective way of changing people attitudes towards conservation.

Another important aspect of the GPP is the vegetation mapping and assessment of the ecosystem degradation of the GPP. This was facilitated through the characterization of the ecosystem which were classified and analyzed. The three categories of ecosystems in the GGNP are forests, woodlands and grasslands. In the forests category, three forest classes in the clusters were identified giving primary or high forest, secondary forest and thickets to explain the heterogeneous morphology of the rainforest canopy [10]. The vast majority of Nigerian rainforest areas have been virtually destroyed by increasing agriculture activities. When rainforests are left undisturbed for a long period of time, a complex layered structure of three distinct tree strata may be discerned: i) the tallest level consisting of the emergent trees which can attain a height of over 40 metres and this may include valuable timber such as afara (terminalia superba) and savannah mahogany (khaya gradifoliola). The crowns of the emergent above the general forest canopy usually develop strong buttresses; ii) the middle level with heights between 15-35 metres forms a more or less closed forest canopy underneath; ii) the third stratum comprises small trees with heights of 2-8 metres [11]. All the tree strata can carry an array of epiphytes (ferns and orchids) and lianas which create an extremely complex plant community that support a large number of birds and insects.

The savannah woodlands are the dominant habitant of the lowland and they have canopy averages of between 25 and 50 per cent. They also consist of pyrophytic, deciduous species with xenomorphic properties in the form of leaf surfaces. During the dry season ground core reflectance becomes dominant creating either green, dry or burnt grasses mixed with either of the foliage, 
sometimes grass may be absent in these areas of the Park due to overgrazing or bush burning, and so may "misclassified" as very 'open woodland' [12]. This woodland vegetation is characterized by its ground cover of coarse tall grasses of 2-3 metres high, with small gnarled trees standing far apart which enable the sun to penetrate to the herbaceous layer of the ground. The usage of the term 'savannah' here refers to the wide array and variety of African vegetal cover which is also applicable to all areas of woodland and grassland within the GGNP.

The grassland is the open savannah areas that are dominated by shrubs and grasses which occur in waterlogged areas. This grassland mostly results from several years of anthropogenic activities aggregated by bush burning, fire wood extraction, heavy grazing and/or trampling. In addition to human impacts, the other possible drivers for vegetation changes, especially the inter-annual climate variation or shift in carbon budget from forest environment has the effect of increasing concentrations in the atmosphere [12]. It has been established that vegetation changes are very drastic in the surroundings of the enclave, most of which are climatically induced. These types of ecosystem classification are highly informative and significant and therefore provide a guide for the evolution of strategies for sustainable development of the Park.

\section{Impact, challenges and constraints}

\subsection{Impact of the GPP activities}

Sommer and Rose noted in pages 9-13 of their edited work, Primates of Gashaka: Socioecology and Conservation of Nigeria's Biodiversity Hotspot that the GPP research in the GGNP is "conservation" [2]. There is no doubt that the GPP has opened up the GGNP, especially with the establishment of Kwano research station. To be able to surmount the challenges of electricity for effective communication, computing, freezing, and storage of biological samples of collected data with the provision of the most secure and stable electricity is a rare feat in Nigeria. This environmentally sound 'power island' has continued to attract visitors, officials and students to visit the camp and learn from the activities of the GPP.

The issue of border demarcation has now become a thing of the past as grazers, settlers and hunters operating on the Nigerian side now know the limits of the Park. The Park now has over 700 beacons demarcating its border of $225 \mathrm{~km}$. This makes patrols and law enforcement easy. This reduces uncertainties that cause conflicts between the Park authorities and the communities.

The Project addressed conservation initiatives for sustainable tourism development through its capacity building and law enforcement strategies. For example, members of the communities were not only engaged as field assistants but also bursary and sponsorships were given to African students including Park staff. This has endeared hundreds of secondary school, colleges and university students who now flock the park every year for their field trips. The project has continued to affect local and foreign eco-tourist to the Park. The generation of 
knowledge on taxonomy of fauna and flora, ecology and animal behaviour, vegetation cover and resources made a very significant impact on the GGNP. The project also established a network of collaborations which spread 33 institutions in ten countries, nine of the partner institutions are based in Nigeria.

\subsection{Challenges and constraints}

Deforestation for farming, unsustainable use of natural resources, overgrazing by livestock, un-prescribed fires and unsustainable hunting have continued to constitute threats to eco-balance and biodiversity. Despite legislation restricting hunting in the GGNP, there is intensive trade in bush meat. Many large animals have suffered a long-term decline as a result of poaching. GPP investigations have established that large animals are on the brink of extinction. For example even though about 1000 chimpanzees can still be found in the Gashaka-KwanoYakupal areas of the Park, the existence of the apes is not as a result of effective protective measures, rather the remoteness and large extent of the Park [13]. Other animals are also shrinking in and around the enclaves of settled pastoralists due to overgrazing, bush burning and ineffective patrols. Consequently, surviving forests are often dried of large mammals due to poaching and hunting, and because conservation measures are difficult to implement.

There are four root causes of these challenges which are highlighted as follows. First, the ineffective implementation of conservation laws leading to unregulated use of natural resources. In spite of the fact that the GGNP receives national and international attention in terms of policy documents, there is little legal protection of the montane forests of the Park. The legal designation as a protected area does not guarantee biodiversity conservation, even though it signals not only the importance and willingness to manage and as well establish the boundaries of the site in principle. Moreover, most staff of the Park has little knowledge or experience for designating protected areas as different land use zones in such special socioeconomic systems.

Secondly, there is lack of cross-border coordination and cooperation for biodiversity conservation. In fact, many of the direct threats are trans-boundary issues especially with the porosity of Nigeria-Cameroon border. For many people, there is no 'boundary' or border and so cross-border coordination is essential if policy actions are to be consistent [13]. Until very recently there has been no coordination between Nigeria and Cameroon border agencies for the conservation of the sites.

Thirdly, there is evidence that the national institutions lack the capacity for effective and sustainable forest management. They also lack the knowledge and understanding of the involvement of local communities in protected area management. This is because conservation must be built on national capacity. The continued occurrence of threats to biodiversity indicates that governments often lack the capacity, knowledge and political will to protect and manage the sites effectively. Although many of the problems associated with ineffective government institutions are engrossed in the national economic situations, some specific areas of planning such as building skills in biodiversity survey, priority 
setting and management planning and engaging local communities can contribute to sustainable solutions [14].

Finally, it is important to mention that local communities surrounding conservation sites and within enclaves and buffer zones lack the know-how and incentives for sustainable management of natural resources. 'Lack of know-how and incentives' here means: i) lack of awareness of the forest functions (for example, watershed protection; ii) breakdown of traditional systems of resource use; iii) lack of knowledge of ways of improving production and value from existing farmlands; and iv) poor marketing leading to undervaluation of forest products [14]. The level of poverty of the population around the GGNP makes them feel they have no alternative to wild resources and as a consequence, forests are cleared for farming, fires are set to create grazing land, livestock are herded at high densities damaging sensitive grassland, and forest resources are exploited at unsustainable levels.

\section{New strategies}

The new emergent strategies discussed here include revisiting the NCF-WWFUK approach, review of national policies, the GEF alternative and Strategic Regional Approach (SRA).

\subsection{Revisiting the NCF-WWF-UK approach}

The earlier conservation intervention strategy by the Nigerian Conservation Foundation (NCF) in collaboration with WWF-UK which was funded by the UK Department for International Trade (DFID) needs to be revisited. The project which started in 1992 in two phases was rounded up in 2002. The strategy was to maintain biodiversity by strengthening the capacity of the institutions of the GGNP to work with local communities in the enclaves and the support zones around the Park to improve their level of participation in conservation and sustainable resource management.

This project has improved the level of communication and understanding between the local communities and the Park authorities leading to the creation of Conservation and Development Committees (CDCs). It also initiated a number of rural development projects in the Park's support zones. Despite such efforts the project was limited in the sense that it did not address the crucial conservation problems, especially the zone around the border between Nigeria and Cameroon. The activities of the GPP have added value to the NCF-WW-UK strategy.

Revisiting this approach will require new tasks of establishing enhanced linkages with government, NGOs and local communities in terms of greater support to the National Park Service Governing Board (NPSGB), more training for Park staff, provision of more infrastructures like roads, ranger posts, tourist chalets, education and training in conservation techniques. Local NGOs can provide institutional support for the NPSGB and encouraging local responsibility for conservation and improved enclave management, research and monitoring. 
New agreements between the local communities and the Board will establish new opportunities for improving livelihood, security and protection of biodiversity. These agreements should establish new conservation rules and regulations and define local rights and responsibilities.

\subsection{Review of national policies}

Over the years, there have been attempts to review policy goals on conservation of biodiversity to ensure sustainable uses of forest resources to achieve the many benefits accruing from soil, water and wildlife conservation for economic development. Among Nigeria's priority programmes are the extension of national parks and reserves and the compilation of their flora and fauna. The Nigerian National Conservation Strategy reviewed the status of biodiversity conservation in the attempt to fill the gaps and develop action plan to bridge the gaps in Nigeria's conservation efforts. The then existing National Policy on Environment being implemented thorough Federal Environmental Protection Agency (FEPA) was transformed into a Federal Ministry of Environment and a new agency, National Environmental Service and Regulation Agency (NASERIA), established to replace FEPA, now pay special attention on biodiversity conservation. Its new strategies include promotion of in-situ/ex-situ biodiversity conservation, increase awareness and understanding of biodiversity and strengthening of the centres for exchange of data and information relevant to conservation of biological biodiversity [13].

This strategy paved the way for community involvement in natural resource management in protected areas. Thus, the GGNP was gazetted in 1992 and the National Parks Law was amended to make provisions for community wildlife management in or outside the parks and also community participation in forest resources management. In 1992 when Gashaka Gumti was designated a National Park, local support was achieved by allowing a number of farmers and pastoralists to settle within the game reserve enclaves. The GGNP has eight enclaves, five of which are located in the highland areas. A support zone was created which defined the area surrounding the Park up to about five km, where stable and compatible land use practices were allowed to give added layer of protection to the Park itself [13]. Although the Park still lacks some basic facilities such as roads, schools and health clinics, the review of conservation laws and strategies has brought the local communities at the forefront of biodiversity management and conservation.

\subsection{The GEF alternative}

Apart from its geographical and socio-economic contexts as an ecoregion, the GGNP has a transboundary context of global biodiversity significance. It provides an ecosystem linkage with the Tchabal Mbabo cross-border region of Cameroon which represents one of the few examples of forests-savannah eco-tones linking Central and West Africa and which have been known to be important for specialisation processes necessary for conservation of various texa. This 'eco-systemic unit' is artificially cut by an international boundary and 
therefore demonstrates the existence of a corridor for migratory animals, socioeconomic interactions through poaching and collection of medicinal plants, as well as seasonal transhumance [15]. Its significance to global biodiversity is that the area is located in an ancient volcanic chain with historic global climatic changes that resulted in high level of endemic plant and animal species. There is consensus among global conservationists that the area is of utmost biodiversity conservation due to its large ecosystem/habitat levels, mammal species and bird species, reptile/amphibian species, fish species, invertebrate species and plant species that are perennially being threatened [16].

The Global Environmental Facility (GEF) has therefore developed an alternative to ensure sustainable conservation of biodiversity of globally significant cross-border sites. The GEF alternative is designed to engage in the planning and establishment of mechanisms for cooperation between Nigerian and Cameroonian authorities responsible biodiversity conservation. The central principle in the GEF alternative is to establish a harmonious management system in both sides of the border that are complementary, consistent and coordinated. The GEF alternative also has the capacity to create mechanisms and structures for protected area planning and management. This would help minimizes conflicts between farmers and pastoralists, farmers and protected area managers in both Nigeria and Cameroon.

\subsection{Strategic regional approach}

The GEF alternative can be combined with a strategic regional approach that addresses the concerns of local communities and building of national and local capacity for protected areas, participatory co-management and encouragement of cross-border cooperation and coordination. Gazetting of protected areas is not enough unless there is partnership with the communities. A new framework should be designed and negotiated with the local communities to address three core operational areas, including establishing core protected areas, multiple use zones, wildlife corridors and technical operations units.

Core protected areas are non-negotiable areas where no activity should be allowed. This will be followed by multiple use zones which surround core areas where regulated human activities can be negotiated. Here communities may be allowed to use and manage resources within a defined area probably negotiated along with other communities according to agreed management plans. Wildlife corridors are key wildlife areas which might be established to allow free movement of wildlife. There should be a technical operations unit with local communities, NGOs, supervising ministries and other stakeholders represented. This would allow integration of development and conservation issues in different sectors. The operations unit should pay special attention to the goals of participatory conservation and management, cross-border cooperation and coordination and sustainable management of natural resources.

This regional approach should be linked with the Regional Action Plan (RAP) for the Conservation of Nigeria-Cameroon Chimpanzees which was launched by GPP in 2011. The Regional Plan seeks to lobby the Federal Government of Nigeria to improve law enforcement and boost funding for ranger training, 
wages and equipment for the conservation of apes in the GGNP. The RAP and GPP can work together to promote national and international tourism to generate income for local communities and the Park. The Plan hopes to review GGNP management plan, particularly with respect to the enclave issues, and to liaise with the Taraba State Government of Nigeria to address issues relating to Park enclaves, encroachment, livestock grazing and fire regimes [17].

\section{Summary and conclusion}

The paper examined the activities of the GPP as part of the emergent strategies for sustainable rural development of GGNP. The focus on biodiversity research, primate socio-ecology and community relations as conservation strategies have opened up the GGNP to the outside world. The study has also exposed the Park as possessing global, regional and national biodiversity conservation significance that requires international attention. Despite the challenges and constraints, the project has made significant impact on biodiversity conservation and sustainable rural tourism development. Thus, biodiversity research has assumed the significance of a conversation strategy.

Many lessons can be learnt from the GPP especially the breakthrough made in the area of provision of infrastructure, like the creation of a 'power island' that serves as an important lesson for Nigeria and Africa, where power supply in rural areas has continued to pose serious challenges. National governments, NGOs and local communities have much to learn about the complexities of biodiversity conservation.

The emergent strategies discussed in the paper need harmonization as they are interwoven, more especially because they address combined efforts of Government, NGOs and Local communities in biodiversity conservation. The regional or sub-regional dimension, as well as the GEF alternative has to be adopted and strengthened. All these approaches de-emphasize top-button approach which relegates local communities in rural resource management.

Looking at the emergent strategies, it is also clear that conservation and tourism development of the GGNP far transcend Nigeria as the area in question cut across Nigeria and Cameroon. This necessitates transboundary collaborations for conservation and management. The existence of a bilateral agreement between Nigeria and Cameroon means the foundation for such collaboration has already been laid; what remains is effective implementation.

From the results of the GPP research, additional and detailed information and facts are still needed to be collected on socio-economic and biodiversity factors, appraisal planning, and weaknesses of wildlife management systems and potentials for development of community-based natural resources management. This requires further collaboration in research and sustainable tourism development. The implication is that biodiversity conservation and tourism development cannot be separated. These collaborative efforts must pay special attention to partnerships for biodiversity conservation, participatory conservation and management, coordination and cooperation, capacity building and 
awareness, public engagement and sustainable management of natural resources across a broad spectrum.

The sustainability of these strategies also requires financial sustainability that carries all stakeholders including governments, NGOs, local Communities and resource users. The federal ministries of Tourism and Culture, Environment and the National Park Board as well as the Nigerian Conservation Formulation should redouble their conservation efforts and collaboration with other national international stakeholders to promote the objectives of biodiversity conservation and sustainable tourism development. The GPP efforts can play a leading role in these collaborative efforts.

\section{References}

[1] Why was Gashaka Gumti National Park Created? Online. http://www.ucl.ac.uk.gashaka/motivations/

[2] Sommer, V. and Ross, C. Exploring and protecting West Africa's Primates: The Gashaka Primate Project in context (Chapter 1). Primates of Gashaka: Socio-ecology and Conservation in Nigeria's Biodiversity Hotspot, eds. V. Sommer and C. Ross, Springer Science+ Business Media: New York, pp.1-37, 2011.

[3] Richard, B., To save a wilderness: the creation and development of Gashaka Gumti National Park, Nigeria (Chapter 2), Primates of Gashaka: Socio-ecology and Conservation in Nigeria's Biodiversity Hotspot, eds. V. Sommer and C. Ross, Springer Science+ Business Media: New York, pp.39-54, 2011.

[4] Gashaka-Gumti National Park, Online. http://www.cometonigeria.com/ wheretogo/national-parks/gashaka-gumti national-park

[5] Weaver, D.G., Where is biodiversity located? Spatial and temporal patterns for a Nigerian tropical forest, GPP Annual Report 11, pp.17-29, 2011.

[6] Weaver, D.G., Height effects and seasonability of dipteran communities in Nigerian tropical forest, GPP Annual Report 12, pp.16-57, 2011.

[7] Gashaka Primate Project, Annual Report No. 11, pp.220-224, 2011.

[8] Bannet, D. and Ross, C., Fulani of the highlands: costs and benefits of living in the park enclaves (Chapter 6), Primates of Gashaka: Socio-ecology and Conservation in Nigeria's Biodiversity Hotspot, eds. V. Sommer and C. Ross, Springer Science + Business Media: New York, pp.231-267, 2011.

[9] Pollard, T. The effects of viewing primate documentaries in attitude towards conservation in Gashaka Gumti National Park, GPP Annuals Report 11, pp.205-218, 2010.

[10] Gumnior, M. and Sommer, V., Multi-Scale, multi-temporal vegetation mapping and assessment of ecosystem degradation in Gashaka Gumti National Park, Nigeria, GPP Annual Report 12, pp. 200-204, 2011.

[11] The low land rainforests of Gashaka, Online. http://ucl.ac.gashaka/rainforest/ 
[12] Dunn, A., et al., Sticking to the rules: working with local people to conserve biodiversity at Gashaka National Park, Nigeria, in Abbot, J. et al., Promoting partnerships, managing wildlife resources in Central and West Africa, Evaluating Eden Series No. 3, IIED, London, pp.128-154, 2000.

[13] Transboundary collaboration for ecosystem conservation: the mountain forests of Gashaka-Gumti Park, Nigeria and Tchabo, Cameroon. Online. http://www.unep.org/training/programmes/Instructor\%20Version/Part_2/A ctivities/Ecosystems/Mountains/Strategies/Transboundary_collaboration_fo r_ecosystem_conservation.pdf

[14] Vabi, M.B., Report of project identification and familiarisation trip to Tchabo Mbabo community hunting group at Tibati and discussion of the execution of socio-economic surveys in Southeast forests. WWF Report, 1997.

[15] Abbot, J., et al. Promoting partnerships, managing wildlife resources in Central and West Africa, IIED, Evaluation Eden Series No. 3, London, 2000.

[16] Stattersfield, J. A. et al., Endemic bird area of the World: priorities for biodiversity conservation, Bird Life International, Cambridge, UK, 1998.

[17] Morgan, B.J. et al., Regional Action Plan for the conservation of NigeriaCameroon Chimpanzees (Pan troglodytes ellioti). IUN/SSC Primate Specialist Group and Zoological Society of San Diego, CA, GPP Annual Report No. 12, pp.226-228, 2011. 